\title{
Korean Interpretations of Western Business Meetings: The Language of Cultural Differences
}

\author{
Jee-won Hahn \\ Kyung Hee University
}

\begin{abstract}
As language education focuses on a variety of units associated with interaction as well as linguistics, it now covers a wide range of skills from grammatical and linguistic to interactional and social competence. This is reflected in the diverse situations and compartment specified in English-teaching activities. This study focuses on business meetings to examine and evaluate how Korean students perceive Western style business meetings. To understand the learner's perception of business meetings, this study employs an analytical framework (Hymes 1974) to take into consideration components accompanied in speech activities. In terms of methodology, questionnaires are drawn up to involve components of business meetings based on Hymes' speaking model. In this study, eleven components are investigated such as settings, ends, act sequences, and key. In many instances, social hierarchy is present in Koreans' consciousness with regards to business communication indicating they are influenced by different cultural values. This study has implications for teaching business communication in English to show cultural interpretation of Western style meetings. Findings of the study provide social and cultural features associated with speaking in the business context. It seems necessary for language
\end{abstract}


30 Korean Interpretations of Western Business Meetings

instructors to help learners they must be aware of differences between cultures and how that would affect how it is being taught or learned. In addition these features are always changing and that must also be taken into consideration.

Keywords: ethnography of speaking, business communication, meeting event, second language learning, culture

\section{Introduction}

In the language-learning environment, diverse forms of English are recognized in different situational factors such as setting (e.g., business English, travel English, public speaking English), genre (e.g., phone English, conversation English, movie English), and channel (e.g., spoken English, written English). These are types that result from drawing contextual and interactional factors. This study is motivated by ESL activities in business communication. As a requirement for students in business related fields, the course of business English provides an opportunity for students to focus on English related to their career path. The goal of course is being able to communicate in a business meeting or setting. Courses such as meetings, interviews, and presentations are popular with students looking to enhance their use of English. While public speaking and interviews are conducted by a single individual (or two) and the imposition to speak is on one person, meetings on the other hand are organized by two or more people and require more advanced language skills associated with interactional competence.

To understand the Korean view of business meetings, this study investigates interpretations coming from a native perspective as well as from a comparative perspective. One is to investigate how Korean learners of English understand types of meetings conducted in English (Section 4). This study looks at the features in British English meetings and how they are affected by speech and 
contextual factors. Learners' interpretations of target language speech behavior can precede and/or hinder learner development in language skills. Another purpose is to examine what business meetings are like to Koreans by exploring some components of the speech event of meetings (Section 5). This study indicates specific instruction to help learners recognize different ways of speaking across cultures. As presented in this study, Korean students have difficulty in utilizing what they learn in class because their social system is different. They utilize their native social system, which is more comfortable, and try to impose that system upon the Western one. This often does not work because there are features in their system are incompatible in the Western system.

\section{Related Studies}

\subsection{Theoretical Framework}

The ethnography of communication aims to describe what one needs to know to be a culturally competent member of a speech community (Hymes 1972). Hymes (1974) argued that a speaker's linguistic ability is not limited to grammatical rules. He further proposed to include knowledge that enables the speaker to use language. This kind of knowledge was termed communicative competence. In order to analyze speech behavior, Hymes (1972) suggested a hierarchy of units (large-to-small): speech situation (including speech genres), speech event, and speech act resulting from an understanding the social activities constituting the social life of a community. From this perspective, speaking in a particular situation is associated with many factors in context.

This framework is used in addressing such issues as who is involved in the encounter and where it takes place (Agyekum 2008; Duranti 1995; Fong 2000; Saville-Troike 1989, 2000; Scollon \& 
Scollon 2001). Duranti (1995) adopted a speech event approach in the description of Samoan. Instead of analyzing individual utterances isolated from conversation, he provided a grammatical description of the sentence or morphemes (e.g., case marking) as one part of the description of higher units, such as speech genres and speech events in order to understand cultural and social interactions from the native's view. Application of the framework to sociolinguistics and linguistic anthropology can be found and a variety of speech activities and acts are investigated. Fong (2000) applied Hymes' model to analyze the Chinese cultural event 'Luck Talk' for the New Year. Different components of the event were identified. Scollon and Scollon (2001) analyzed professional discourse from the ethnography of communication.

The notion of communicative competence refers to the acquisition of knowledge as to when to speak, when not, and as to what to talk about with whom, when, where, in what manner (Hymes 1974). An individual violates cultural norms from a lack of understanding of the behaviors reflecting appropriate cultural meanings, norms and rules because individuals interact based on cultural perspectives of what constitutes communication competence. Extending this notion to second language contexts, researchers (Kramsch 1993; Wolfson 1989) explored knowledge of social values of the target culture and the ability to produce appropriate to produce appropriate strategies used in a particular situation. Their concern is to see how communicative competence in an L2 can be effectively achieved. To understand communicative behavior, I focus attention on the situation in which the speech occurs, identifying components such as the content of the message, manner to tone, and verbal exchanges.

\subsection{Studies on Korean Business Communication}

In English, the word 'meeting' is generally understood to refer to 
a group of people coming together in a formal setting usually to discuss a predetermined topic such as business or event planning. The Korean equivalent of English meetings is hoeui consisting of two morphemes hoe 'gather' and ui 'discuss.'

Studies on Korean business discourse are found in a few studies (Suh 2007; Jung 2005 a; b) including one dissertation-length volume and research articles on written business communication. Suh (2007) investigated non-native speakers of English for their use of English in the context of business including Koreans. The data come from meetings between Korean sellers and seven different countries (Finland, France, HongKong, Italy, Japan, Taiwan, and Thailand). The data recorded for 10 hours of seven business meetings were analyzed within conversation analysis. Suh analyzes negotiation in business meetings within conversation analysis focusing on linguistic, interactional and sequential aspects of speech. Then, differences in non-native English are found for lengthy, sequentially complicated and structurally elaborate from a micro analysis perspective. Jung (2005a; b) likewise analyzed written communication in Korean. According to these studies, social power plays a crucial role in the choice of politeness strategies.

\section{Data Collection}

A survey on business meetings was conducted in a business English course at the end of the semester. The course was designed to provide serial language and interactional skills necessary for students with the goal of students being capable of actively participating in business communication. The English materials used in the course include audio-recorded conversations occurring in a variety of situations and different types of meetings from the textbook English for Meetings spoken in British English. To be a member of a meeting, relevant speech activities include exchanging 
greetings and small talk, expressing one's opinion, expressing agreement and disagreement, negotiating, and closing a meeting. After the course was completed, at the end of the semester, students were asked to express their views and ideas on meetings mainly coming from British English business communication.

The questionnaire consists of a total of eleven items, and students were asked to write appropriate responses for each question (see Appendix). These items were selected based on the ethnography of communication. To investigate perception of meetings in general and in Western style, the ethnography of communication provides a descriptive view of Korean participants' norms of interpretation, rules of speaking, and norms of interaction (Hymes 1964; 1972). In selecting question items, this study adopts the view proposed in the ethnography of communication to understand Korean learners' perceptions of Western meetings from a broad perspective. Settings, key, norms, and speech acts are investigated. Total questions are drawn into two parts depending on the nature of content. Components like setting, norm, and ends are used to examine general aspects of meetings while those like speech acts, key, content are used to find out perception of British business meetings.

The survey was conducted in two courses taught by the author and a colleague, with a total of 46 students participating. The survey was conducted anonymously to relieve pressure with evaluation. The instruction does not require any personal information. Participation was voluntary and students were asked to explain themselves thoroughly.

\section{Interpretation from a Comparative View}

For British business communication, three components are investigated: common speech acts, Western-sounding speech acts, key, and instrumentality. Act sequences are investigated in two 
ways: common and Western-sounding speech acts.

\subsection{Act Sequences - Common}

From the Korean point of view, two main categories are identified as common speech acts occurring in Western business meetings: opinion-related and chairperson's speech. Overall, opinion-related acts are considered the most common to Koreans. Korean learners include exchanging opinions as the most common speech behavior in meetings.

(1) Common speech acts in Western business meetings

Opinion-related acts (23)

Opinion-making acts (17)

Opinion-encouraging acts (6)

Chairperson's speech (8)

Extra (1)

For opinion-related acts, two categories are suggested: opinionmaking and opinion-encouraging acts. The distinction between them comes from opinions toward the speaker or the listener. A set of opinion-related acts include making a point, disagreement and agreement that the speaker is able to convey. The second opinionrelated acts refer to those which encourage the hearer speak out, termed as opinion-encouraging acts. These acts provide environments in which participants are actively able to participate in a meeting. Positive responses, small talk, and joking are included in the latter category.

Many responses are related to expressing opinions such as making a point, agreement, and disagreement. Seventeen out of 46 participants responded to making a point and expressing opinions. As devices to encourage the speaker to speak and in order to encouraging expression of opinions include respect, 6 responses 
involve opinion-encouraging acts. It is interesting to note that Koreans pay attention to the use of language which help to establish social rapport and encourage joking, small talk, and positive response.

Phrases and questions used to express opinions are the most, in the data illustrated in (2):

(2) Making an opinion

Can I make a point?

In my opinion...

I think that...

From an interactional perspective, responding to the other's opinion is realized in terms of agreeing and disagreeing with the other. Particularly, disagreement is a common type of speech in Western business meetings.

(3) Expressing disagreement

I'm afraid I can't...

I'm sorry to interrupt.

I'm afraid but I...

Eight respondents pointed out chairperson's speech. For chairperson's speech, the announcement of a meeting is an example, as follows:

(4) Let’s get down to business.

\subsection{Act Sequences - Western Style}

Responses to 'foreign' and 'Western' style speech acts are answered in two ways depending on acknowledging Western or not. Seven respondents out of 46 do not agree with the term 'foreign' and 'Western' style of speaking and deny Western distinction from 
Korean type of speech. They see the two cultures tend to merge and point out that Korean society becomes Westernized. For those who find Western style of speaking, Western way of speaking appears in the two dimensions: linguistic and non-linguistic. Non-linguistic features include components such as the flow of a meeting and scheduling event.

(5) Western-style speech acts

Linguistic features (23)

Non-linguistic features (2)

Speech acts particularly characterized as 'Western' and 'foreign' are grouped into three categories, as follows:

(6) Western-style linguistic features

Opinion-involving acts (11)

Positive politeness (9)

Extra (2)

What is considered as foreign and Western appear in the act of making a point and its relevant acts. Speech acts termed Western style or foreign are distinguished from those classified as common ones (Section 4.1) because the former is based on those that are quite different from Korean and not frequently seen in Korean society. Acts to show active participation in discussion and debates are included. For this reason, interruption (5 instances) is included in exchanging opinions. To represent aggressive expression and confidence, interruption is counted as foreign. Nine responses are classified as positive politeness coming from Brown and Levinson (1987)'s theory on politeness. According to Brown and Levinson, politeness strategies are divided into two types based on face. The strategies identified in this study appeal to 'self-image' of the hearer including small talk, joking, and complimenting. Even though there are 
criticisms for Brown and Levinson's politeness theory in the literature, the distinction between the two types of politeness seems to be useful for the current study. Here, the term 'positive politeness' is closer to involvement (Scollon and Scollon 2001: 4651) or solidarity (Garcia 1996), which emphasizes wants to establish social connection. According to this finding, responses to the question of sounding 'foreign' speech acts share similarity with common speech acts. Opinion-related acts are counted as Western as well as common.

\subsection{Key}

In describing the tone and spirit for British business communication, responses consist of three categories depending on the content of descriptive terms: positive, negative, and neutral. The tone of business meetings in Western culture is described by positive evaluative terms such as 'open-minded,' 'active' and 'enthusiastic.' Interactions among colleagues are characterized in terms of 'enthusiastic,' 'active' and 'direct.' Many responses refer to scenes in which members participate in a discussion and the way of exchanging talk and proposing ideas.

(7) Mood of Western style meetings

Positive description (31)

Negative description (4)

Neutral description (1)

More responses point out positive meaning occurring: 31 regarding the mood of meetings. On the other hand, relatively negative meanings are identified at four in the data. In describing the mood of meetings in Western culture, 'awkwardness' and even 'static' is the feature to describe western communication culture. Such interpretation can be understood in relation with the use of non-authentic data 
from textbook materials in class. Students' responses are mainly based on experiences with class activities listening to workplace talk among native speakers of English. For this reason, participants may see lack of naturalness in the way of speaking in meetings as if set up and made up as a scenario.

\subsection{Instrumentality}

The instrumentality commonly used in a meeting that participants note is email (occurring in 30). The use of the telephone is also preferred, occurring 16 times. For instrumentality, using email is counted as the most common way of delivering message next to face-to-face contact.

(8) Instrumentality

Email (27)

Telephone (13)

Both email and telephone (3)

Extra (3)

\subsection{Differences Between the Two Cultures}

Regarding cross-cultural differences, not all respondents acknowledge differences between Korean and Western style meetings. Seven responses do not see cross-cultural differences; they state that Korean society becomes Westernized as it is exposed to international business and globalization.

(9) Views on cross-cultural differences

Acknowledging differences (29)

Acknowledging no differences (7)

Features identified as fundamental differences in the data appear in 
40 Korean Interpretations of Western Business Meetings

two aspects. The first difference is found whether the presence of social status exists or not. These responses see hierarchical system in Korea while they don't in British. The second is on descriptive terms characterizing the mood of business meetings based on oppositions (e.g., 'serious’ vs. 'friendly.')

(10) Differences in business meetings

Presence of social rank (8)

Descriptive terms for mood (20)

Intimacy (1)

Eight Korean respondents directly mentioned cikcha $k$ 'social rank' or ciwi 'status' as fundamental differences referring to social hierarchy. According to these respondents, social status can affect several aspects in business meetings. First, rank may restrict one's ability to freely express one's opinions. For this reason, opinions are restricted according to the social rank of members in Korea, while this is not so in Western culture. Secondly, aspects relevant to social rank were found in the perception of the chairperson, the status of whom is greater in Korea. As an extension of conscious of social status, two responses involve the role of a chairperson and the greater status in Korean meetings. Twenty responses see a difference in terms of the way how business meetings are described. Terms such as 'formal', 'serious' and 'static' refer to the Korean way of conducting a meeting while those such as 'open-minded' and 'enthusiastic' refer to Western-style meetings. As a factor contributing to the mood of active participation, interruption is noted in Western culture. On the contrary, lack of rules in interrupting behavior is counted in Korean. According to views on interruption in business meetings, less use of interruption and the low frequency of interruption is the feature of Korean compared to the Western context. On the other hand, interruption is described as occurring without any restriction causing the impression of rudeness. 
Overall, features recognized as fundamental differences between Korean and Western communication culture tend to be in the social systems. The first feature is directly related to the awareness of hierarchy including words meaning 'rank.' For the mood of the two cultures, consciousness of different social system may lead to describing the overall sprit of meetings resulting in oppositions based on social restriction. Particularly, the opposition terms 'horizontal' and 'vertical' clearly shows the consciousness of different social systems.

\section{Interpretation from a Native View}

Section 4 examined business meetings from a comparative perspective. More speech and contextual components are investigated from a Korean native's view for understanding the way people speak and interact in the business context.

\subsection{Settings}

Speaking as a physical phenomenon consists in a concrete place and time. Settings influence the mood of speech event. For instance, the choice of lobbies may make speech informal compared to that of conference rooms. Most responses are answered with respect to time and place. For time, there are three categories in relation with working hours. Many responses consider the best time should occur during working hours (35 out of 46). These responses include specific time, that is, morning time and afternoon time. There are more responses for preferring morning meetings (16) to afternoon meetings (13). For using time after work, one available time is to use lunch time. 
(11) Time for meetings

During working hours (35)

Besides working hours (5)

No restriction on time (according to needs) (3)

Places good to hold a meeting involve three kinds such as offices, conference rooms, and lobby. Individual offices are the most preferred among the responses. It is interesting to note that some perceive that a meeting is likely to be held in the office of someone who is higher in social rank. For this reason, they suggest a chairperson's office.

(12) Place for meetings

Private offices (13)

Meeting rooms (2)

Lobby or chatting room (2)

\subsection{Topics of Small Talk}

Small talk is an important part in social encounters for rapport and building social harmony. Participants are likely to exchange greetings and brief talk in order to the break ice. Main topics likely to be broached during small talk include work-related, transportation-, and participation-related questions according the data. Korean respondents prefer the three main questions. For small talk, the topic most likely to be raised in private interaction between colleagues, the question work experience ('How long have you worked?), is chosen the most in 15. Questions about transportation ("Did you come here by plane") and participation for the meeting ("Is this the first time you've come here for a meeting?”) follow. For Korean learners, asking about work experience is counted as something very likely to ask someone in a meeting, which can be seen coming from awareness of the business context. 
(13) Topics in small talk

Work-related question (15)

Transportation-related (12)

Participation-related (12)

Place of stay-related (7)

Extra (5)

\subsection{Ending Meetings}

Ending meetings influences participants toward what directions verbal interaction is geared. Regarding the purpose of holding a meeting in the business context, results are by large divided into two views. The first view sees meetings as a way of finding concrete solutions, while the second see it as a way finding new ideas and opinions. The first view places emphasis on the final production and conclusion. The end result of having a meeting is finding conclusion or a better solution. On the other hand, the second view emphasizes the meeting as a way of drawing up new ideas. These responses use terms uikyen 'opinion,' which can be termed as process-based view.

(14) End of meetings

Production-oriented view (27)

Process-oriented view (17)

\subsection{Norms}

Meetings are likely to be conducted by two or more people. As implicit rules governing interactions with the other, norms refer to in what ways participants talk each other. They include rules of politeness among participants. Rules expected during business meeting interactions can be grouped as considering the other (participants) and considering non-participant factors. For specific ways of respecting the other, careful listening, avoiding interruption and 
non-relevant (too personal story) are proposed. Another rule is being able to pay attention and listening to what the others have to say. When people are not the primary source of consideration, nonparticipant factors including timing, the flow of meetings and general behavior rather than what is said are emphasized.

(15) Rules expected

Considering participants (42)

Considering non-participant factors (4)

\subsection{Reaching an Agreement}

Similar to ending meetings, consensus in a meeting affects the direction in which way participants lead the meeting. Not all participants see achieving consensus as necessary for holding a meeting. Views on reaching an agreement are divided into two parts: obligatory and optional view. Those who take the view that reaching an agreement is obviously necessary part of a business meeting in the data occur 34 out of 46 responses. These respondents see the importance of consensus in a meeting. The underlying assumption is reaching an agreement is viewed as the goal of holding a meeting. Those who see consensus as obligatory in the act of participating in a meeting take agreement as the goal of a meeting. They regard consensus as inevitable part of a meeting. On the other hand, for those who don't see meetings necessarily end in consensus (occurring in 10), they put emphasis in exchanging opinions and the process. Diversity is valued in the second group. They put more value in drawing up ideas and in exchanging each other's opinions.

(16) Two views on consensus Consensus-obligatory view (34)

Consensus-optional view (10) 


\subsection{Procedure of Decision-making}

When conflicts in opinions are strong, three different methods are suggested: compromise, voting, and hiring a chairperson as a mediator. Among them, participants see compromising conflicts in opinions primary in decision-making procedure at 22. Specific forms of mediation include acts like negotiation and mediation. Taking a break and arranging the next meeting can be seen from the same idea to seek further negation. Voting is the second most preferred in the data occurring 14 times. Decisions assigned to a person who is in power is suggested as the third way of dealing conflicts. The role of a mediator is noted and for this reason, and nine responses assign decision role to a chairperson.

(17) Procedures of dealing with conflicts

Compromise (22)

Voting (14)

Chairperson's decision (9)

\section{Discussion and Conclusion}

Within politeness theory (Brown and Levinson 1987), results of this study indicate learners pay attention to a set of verbal strategies classified as positive politeness. Positive politeness is counted as features characterizing business meetings in Western culture. Verbal strategies include joking, small talk, and compliments, which emphasize solidarity for the relationship. Attention to such strategies needs to be paid in the ESL classroom. Korean learners' attention to such type of politeness may be lacking in Korean language. In Western business communication, the most striking speech act involves interactional skills with opinions. The environment to encourage active participation in discussion and exchanges of ideas 
is another feature identified by Korean respondents. Lack of positive politeness, rare in the Korean context may be striking to Korean learners. As Korean students perceive it, it seems necessary to pay attention to solidarity strategies from a pedagogical perspective.

According to this study, politeness strategies and key of meetings are influenced by social aspects of communication. Korean perceptions of some characteristics for business meeting in Western culture is related to social status. Their recognition of social hierarchy is striking in several aspects. For instance, in selecting a place for holding meetings, Koreans believe a meeting is likely to be held under someone who is higher in status, and the possible settings for meetings are suggested in terms of a chairperson's office. They are likely to see unequal distribution of power in the meeting event.

Another feature of Korean sensitivity to social status can be found in the ways of looking at a chairperson. In describing the role of a chairperson in Western culture, the chairperson is described as a member of the meeting, distinguished in his or her task. However, from a Korean perspective, a chairperson represents social status. Koreans see greater power in the chairperson's position. For the decision-making process, the final decision can be mediated by someone of highes status in a meeting. The idea of depending on the chairperson's decision for dealing with conflicts in a meeting reflects the fact that the role of the chairperson is not simply limited as a mediator. For Korean learners, social hierarchy plays a crucial role in perceiving differences between Korean and Western styles in the business context as well.

Cultural differences in the way of speaking may influence learners' perception of Western style business meetings. Stereotyped unnaturalness identified in the data is the case. There are responses mentioning unnaturalness in British business communication. These participants see 'static' and 'stereotyped' in western culture. Cultural differences may be represented as if conversations are set up. For this reason, in describing the mood of Western business meetings, 
perception of Western meetings in terms of 'unnatural'. They may represent their impressions from British communication, which are different from the Korean way of speaking regarding interactional aspects and starting a conversation and responding, interrupting and disagreeing. This reaction needs further consideration in order to improve language skills by paying attention to different communication styles. Prior to presenting English-speaking materials to learners, it is necessary to provide instruction on social and cultural information associated with speaking. Learner's low proficiency in language skills may need to be considered from their difficulty in using a second language as a result of the interference from his or her native concept. Those with strong native view might have more difficulty with being familiar with the 'new' ways of speaking. Even though class activities and textbooks involve a plenty of linguistic materials, learners are limited to apply them when they maintain their native views.

On the other hand, unnaturalness identified in students' responses can be conceivable from a methodological perspective. In this study, audio-recorded conversations from ESL textbook materials are used for examining perception of Western culture. As the Koreans pointed out, the impression of being stereotyped may come from unnaturalness compared to natural speech. It remains for further study to examine whether Koreans still see stereotyped speech even in naturally-occurring data. If the follow-up study presents similar findings involving stereotyped or static impressions, it would tell us that the findings of this study apply regardless of kinds of testing materials.

As researchers (Davies 2004; Spencer-Oatey \& Xing 2003) argued, using native speaker's interpretation and judgment is important for understanding cross-cultural communication. Inspired by such an approach, this study used perception data to investigate business communication in Western culture. In teaching or learning a foreign language, concrete and specific units of speech become 
common in ESL textbooks. The genre-based approach in ESL can be seen as the result of such interest in second language acquisition. A variety of English skills diversified in the ESL environment to provide practical language skills tends to be associated with recognition of culture and context. Emphasis on linguistic level such as presenting English-speaking materials to language learners should be complemented by instruction in context. Due to advanced technology and media (and the Internet), language learners have been able to access to English speaking materials more than ever. Despite this, many learners still have difficulty in learning new ways of speaking. Being able to participate in a speech behavior requires skills for language as well as knowledge about context. Language learners are likely to seek ways of speaking according to their norms of their native language. According to personal experiences, language learners have difficulties in acquiring knowledge if the knowledge is quite new to them. Learners are unconsciously likely to speak in the way as they typically do in their native language.

\section{References}

Agyekum, K. 2008. The Pragmatics of Akan Greetings. Discourse Studies 10.4, 493-516.

Brown, P. \& Levinson, S. 1987. Politeness: Some Universals in Language Usage. Cambridge: Cambridge University Press.

Davies, Catherine E. 2004. Developing Awareness of Crosscultural Pragmatics: The Case of American/German Sociable Interaction. Multilingua 23, 207-231.

Duranti, A. 1995. Language in Context and Language as Context: the Samoan Respect Vocabulary. In A. Duranti \& C. Goodwin (eds.), Rethinking Context, 77-99. Cambridge: Cambridge University Press.

Fong, M. 2000. 'Luck Talk’ in Celebrating the Chinese New Year. 
Journal of Pragmatics 32: 219-237.

Garcia, C. 1996. Reprimanding and Responding to a Reprimand: A Case Study of Peruvian Spanish Speakers. Journal of Pragmatics 26, 663-697.

Hymes, D. 1964. Introduction: Toward Ethnographies of Communication. In J. Gumperz \& D. Hymes (eds.), The Ethnography of Communication, 1-34. Washington D.C.: American Anthropologist. . 1972. Models of the Interaction of Language and Social Life. In J. Gumperz and D. Hymes (eds.), Directions in Socio-linguistics: The Ethnography of Communication 35-71. New York: Holt. . 1974. Foundations in Sociolinguistics: An Ethnographic Approach. Philadelphia: University of Pennsylvania Press.

Jung, Y. 2005a. The Rhetorical Structure of Korean Business Writing.

Linguistic Insights - Studies in Language and Communication 24, 347-368.

2005b. Power and Politeness in Korean Business Corresponddence. Linguistic Insights - Studies in Language and Communication 29, 291-312.

Kramsch, C. 1993. Context and Culture in Language Teaching. Oxford University Press: Oxford.

Saville-Troike., M. 1989. The Ethnography of Communication: An Introduction. New York \& Oxford: Basil Blackwell.

Saville-Troike, M. 2000. The Ethnography of Communication. In Sociolinguistics and Language Teaching (5th edition.), S. McKay \& N. Hornberger. Cambridge University Press. 351-382.

Scollon, R. et al. 2001. Intercultural Communication: A Discourse Approach ( $2^{\text {nd }}$ edition). Oxford: Blackwell.

Spencer-Oatey, H. et al. 2003. Managing Rapport in Intercultural Business Interactions: A Comparison of Two Chinese-British Welcome Meetings. Journal of Intercultural Studies 24.1, 33-46.

Suh, J. 2007. Organization of Other-initiated Repair in English Lingua Franca Business Negotiation. Ph.D Dissertation. Teachers College. Columbia University. 
50 Korean Interpretations of Western Business Meetings

Thomson, K. 2007. English for Meetings. Oxford University Press. Wolfson, N. 1989. Perspectives: Sociolinguistics and TESOL. New York: Newbury House Publishers.

\section{Appendix}

\section{Translation of the Questionnaire}

Instruction: Questions 1 through 5 is about your experiences with business meetings conducted in British English. Questions 6 to 11 asks about general features that you think a business meeting is like. All answers are anonymous.

1. What are common speech acts in a Western meeting?

2. You've heard a variety of types of conversation. Is there any that you think is 'foreign' and 'quite different'? If then, what is the one?

3. How would you describe the mood of Western style meetings?

4. What is the second most common means of conveying a message than speaking?

5. Do you think there is a difference between Korean style meetings and Western style meetings? If then, what is the difference?

6. What do you think is common time and place for holding a meeting?

7. What would you say among the following possible topics?

8. What do you think is the purpose of holding a meeting?

9. What do you think are rules that members need to follow?

10. Do you think reaching an agreement is important in a meeting?

11. How do you think participants are able to deal with opinions and reach an agreement?

Jee-won Hahn

Department of the Humanities, Kyung Hee University

1 Hoegi-dong, Dongdaemun-gu, Seoul 130-701, Korea

Phone: +82-(0)2-961-0224; Email: jeewonh@khu.ac.kr

Received in Feb, 2010; Reviewed in Mar, 2010; Revised version received in Mar, 2010 